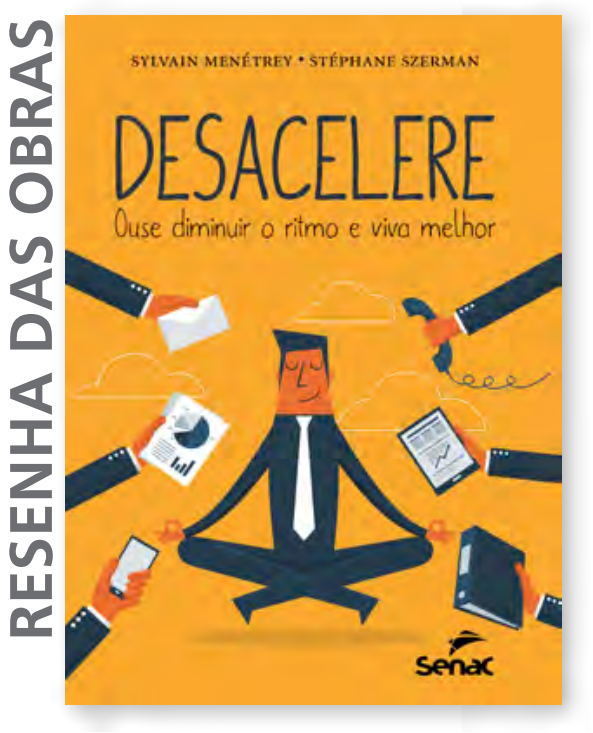

MENÉTREY, Sylvain; SZERMAN, Stéphane. Desacelere: ouse diminuir o ritmo e viva melhor. São Paulo: Ed. Senac São Paulo, 2016.

\title{
Por tempos mais humanos em todas as atividades da vida
}

Em 1973, quando ingressei no Senac em São Paulo, a Instituição tinha uma divisão de formação acelerada, repercutindo sugestão da Organização Internacional do Trabalho (OIT) de que a capacitação para o trabalho deveria acontecer com rapidez. Esse mesmo sentimento de urgência aparecia em movimentos de aprendizagem acelerada de idiomas e de alfabetização precoce das crianças. Predominava a crença de que era preciso reduzir os tempos investidos na educação. Parece que a tendência em acelerar a educação perdeu impulso, embora o encurtamento de períodos continue a ser um valor para pais que lutam na justiça para que seus filhos iniciem sua escolarização formal antes dos seis anos.

A valorização da rapidez aparece também nas maneiras pelas quais se vê a inteligência. Testes para aferir capacidades intelectuais exigem das pessoas soluções de problemas em espaços de tempo bastante reduzidos. O mesmo acontece com testes padronizados para medir resultados de aprendizagem escolar. Num e noutro caso, o pressuposto é que inteligência e rapidez estão associadas. Predomina a crença de que as pessoas mais inteligentes são mais rápidas.

A rapidez aparece também como valor no mundo da tecnologia. Lembro-me de que o uso de sistemas computacionais era marcado por esperas 
bastante longas por resultados. Em 1983, eu e meus colegas de mestrado e doutorado na San Diego State University esperávamos sem estresse cerca de uma hora para ativar o SPSSx (um programa de análise estatística) nos terminais do mainframe da universidade. Hoje, alguns segundos de atraso no funcionamento de um programa de computador levam usuários ao desespero.

Tempos mais relaxados na vida continuam a ser vistos como sinal de preguiça. Tempos acelerados são vistos como sinal de compromisso com resultados, como indicadores de responsabilidade. Esse modo de ver a vida, no entanto, vem sofrendo contestação, ainda incipiente, mas já expressiva em termos de possíveis mudanças. Correr já não é necessariamente uma virtude. Ir mais devagar pode ser um caminho aceitável e até preferido. Devemos isso ao que vem sendo chamado de Slow Movement.

A valorização da rapidez começa a ser criticada no mundo todo. Esse é o tema de Desacelere: ouse diminuir o ritmo e viva melhor, de Sylvain Menétrey e Stéphane Szerman (2016). Os autores iniciam seu livro citando Carl Honoré, jornalista que escreveu uma obra pioneira sobre o assunto ( $\mathrm{HO}-$ NORÉ, 2005), mas não mencionam o fato que levou Honoré a abandonar suas crenças de que era preciso fazer tudo de maneira acelerada. Convém registrar resumidamente a história do jornalista. Enquanto esperava embarque no aeroporto de Roma, ele viu uma matéria que Ihe chamou atenção, uma reportagem sobre histórias infantis de um minuto. O texto fazia referência a projeto editorial que convertia histórias infantis clássicas em narrativas cuja leitura não levaria mais que 60 segundos. Honoré achou inicialmente que aquele projeto era maravilhoso. Era solução para o tempo reduzido que ele tinha para contar histórias para seu filho nos fins de noite.

Honoré ficou horrorizado com seu entusiasmo inicial por histórias infantis de um minuto. Lembrou-se de que seu filho sempre queria que as narrativas, mesmo as já conhecidas, se alongassem, vibrava quando o desfecho demorava a chegar. As histórias infantis oferecem oportunidade para que pais construam uma relação afetiva com os filhos. Riqueza de detalhes, desfechos alongados, tempos de espera sem pressa são requisitos importantes em tais narrativas. A rapidez empobreceria a história. E, mais que isso, empobreceria a relação entre pai e filho. Honoré resolveu então investigar os efeitos perversos do culto à velocidade.

Sylvain Menétrey e Stéphane Szerman andam pelo caminho aberto por Carl Honoré, porém sem as motivações pessoais que levaram este último a examinar a resistência à cultura da velocidade. O livro dos dois primeiros autores é um estudo com certo grau de afastamento pessoal quanto às direções dos movimentos que propõem ritmos menos velozes ao viver. 
Há muitas consequências indesejáveis da cultura que elege a rapidez como virtude inconteste. Os autores de Desacelere, na Introdução, descrevem o quadro geral do culto à velocidade, chamando atenção para o consumismo que depreda os recursos não renováveis do planeta. E esse ataque acelerado à natureza resulta em produção cada vez maior de resíduos que não sabemos onde despejar. A obra narra, por exemplo, o caso das Ilhas Seychelles, que reservaram uma de suas unidades exclusivamente para receber o lixo produzido por formas aceleradas de consumo. A ilha reservada para acomodar as sobras inservíveis do país, em pouco anos, ficou abarrotada de lixo, e este começou a invadir o belo mar turquesa, que é uma das principais riquezas das Seychelles. A lógica da velocidade sem limites acaba se refletindo em uma leitura do progresso tecnológico como consumo cada vez mais rápido daquilo que produzimos.

Nós vivemos, contudo, na era da obsolescência programada. Nossas ferramentas são concebidas para durarem apenas um tempo determinado, a fim de que sejam substituídas por novos aparelhos e que o consumo faça girar a máquina econômica (MENÉTREY; SZERMAN, 2016, p. 24).

Segundo os autores, movimentos da agenda slow não são radicalmente contestatórios dos mecanismos de mercado que alimentam crenças de que é preciso correr cada vez mais. As iniciativas slow não sugerem rompimento e confronto com o mercado. Elas propõem moderação. Assim, embora algumas direções sugeridas pelo Slow Movement guardem semelhanças com ideias radicais e contestatórias dos movimentos sociais dos anos 1960, os apelos na direção de uma vida menos frenética são articulados muito mais para educar as pessoas que para eliminar a velha ordem.

\section{A velocidade à mesa}

O crescimento avassalador de cadeias de fast food é uma ameaça às tradições e culturas locais. A padronização universal do que é servido em balcões de uma rede como a McDonalds varre do horizonte pequenos restaurantes locais, que servem alimento barato produzido com itens cultivados na região. Essa questão incomodava sobretudo regiões da Europa com uma culinária local com fortes raízes culturais e históricas. Por essa razão, as redes de fast food algumas vezes flexibilizaram seus rígidos padrões em certas partes do velho continente. Mas essas pequenas concessões foram insuficientes para sanar contradições entre a comida rápida e os velhos hábitos alimentares. Para conservar tradições culinárias locais, contrapondo-se à globalização imposta pelas redes de fast food, surgiu, em 1989, um movimento que adotou o rótulo de Slow Food. 
É comum a imagem de pessoas engolindo rapidamente comida em casas de fast food ou até mesmo comendo apressadamente sanduíches na mesa de trabalho ou em reuniões da empresa. A rapidez tem aí dupla face. O alimento consumido é preparado em pouco tempo. $\mathrm{O}$ ato de se alimentar é uma atividade apressada, sem dar lugar à apreciação da comida e a uma oportunidade de convivência que um almoço ou um jantar pode proporcionar. Essa urgência que tende a eliminar o ato da alimentação como oportunidade social de encontro com colegas e amigos, e como atividade prazerosa, gerou recentemente, em conversas sobre nova lei trabalhista, propostas de que os trabalhadores não precisam mais do que 15 minutos para suas refeições no período laboral. A ideia não é nova e foi criticada acidamente em cenas do clássico de Carlitos, Tempos Modernos.

A proposta do Slow Food não se restringe ao ritmo mais sossegado na preparação e no consumo de alimentos. Ir mais devagar à mesa não é o objetivo central do movimento. Mais importantes são a educação do gosto e o desenvolvimento do prazer que pode ser proporcionado por alimentos locais. Ao contrário das tendências de produção alimentar padronizada, que acaba reduzindo drasticamente as espécies animais e vegetais, promovendo apenas aquelas plantas e animais com alto rendimento em termos de lucro, o movimento Slow Food propõe uma culinária que valoriza alimentos baseados em produtos regionais. Uma das metas do movimento é proporcionar prazer à mesa. Um prazer que nasce da capacidade de se apreciar as inúmeras diferenças de sabor que variedades de vegetais e animais podem proporcionar. Além de mudanças no hábito de se alimentar, o Slow Food articula iniciativas para que pequenos agricultores possam comercializar localmente sua produção, preferencialmente, em encontros diretos com os consumidores.

O Slow Food tem, portanto, consequências em termos de modelos de produção agrícola. Ele se contrapõe ao modelo que investe em tecnologias que buscam promover apenas produtos para o mercado global. Ele sugere respeito à sazonalidade, em vez de estruturação de um mercado que globaliza a alimentação a tal ponto que cessam as diferenças entre países e continentes. Para manter o fast food, é preciso reduzir drasticamente o número de alimentos cultiváveis. Das centenas de espécies de batatas, por exemplo, apenas quatro ou cinco circulam nos mercados globais. As demais vão desaparecendo. Uma das consequências disso é o empobrecimento dos estoques genéticos dos vegetais. Coisa semelhante está sendo feita com os animais. A crítica inicial à homogeneização dos alimentos não tinha como alvo questões como as de preservação de estoques genéticos, mas isso acabou decorrendo de entendimentos de que o prazer à mesa depende muito de diversidade de opções e sabores. Assim, um movimento cujas raízes eram mais voltadas para a cultura culinária acabou se articulando com propósitos preservacionistas e de desenvolvimento de mercados locais para pequenos produtores. 
Os autores não aprofundam as decorrências educacionais de hábitos alimentares baseados em consumos de produtos naturais produzidos localmente. Mas militantes do Slow Food já avançaram muito em projetos que articulam produção de alimentos com educação. Um dos exemplos mais conhecidos nessa direção é o Edible Schoolyard, projeto desenvolvido em uma escola pública de Berkeley por iniciativa da chef de cozinha Alice Waters (WATERS; DUANE, 2008). Nessa escola, há hoje área de cultivo assemelhada a um sítio, onde se planta grande variedade de vegetais comestíveis. O plantio e cuidado com as plantas é uma atividade regular dos alunos da escola. Não se trata de uma horta escolar. O local de plantio é muito mais amplo que o de uma horta. Plantam-se cerais, cultivam-se frutas, cultivam-se flores, criam-se galinhas, plantam-se hortaliças. Professores de história, biologia e de comunicações participam do empreendimento. Plantio e cultivo de cereais, por exemplo, são referências utilizadas para conversas sobre a importância dos diversos tipos de grãos no surgimento das grandes civilizações. A história, assim, vai para o campo e ganha uma concretude e significado que jamais seriam obtidos em sala de aula. Agricultores da região contribuem com seus conhecimentos e apoio para que os alunos experimentem com muita intensidade o cultivo de mais de três dezenas de plantas.

O Edible Schoolyard não é apenas uma experiência de cultivo. A produção vai para a cozinha da escola, onde os alunos, orientados por uma cozinheira, produzem alimento para consumo próprio e de outros colegas da escola. Experienciar a diversidade alimentar, assim como os prazeres que os diversos sabores podem proporcionar, na linha do Slow Food, é o desfecho de todas essas atividades que os alunos desenvolvem na escola que aceitou o desafio proposto por Alice Waters, o de converter uma vasta área coberta de asfalto em um sítio onde alunos e professores pudessem construir uma educação inspirada pela produção, preparação e consumo de alimentos frescos.

O projeto inspirado por Alice Waters vai na direção que Menétrey e Szerman (2016, p. 49) apontam:

A gastronomia é o conhecimento fundamentado de tudo o
que se relaciona com o homem enquanto ele se alimenta.
Partindo dessa leitura holística da gastronomia dada pelo
grande aforista francês [Anthelme Brillat-Saverin], o Slow Food
determina que a gastronomia não é redutível unicamente ao
prazer dos sentidos como geralmente se tem a tendência de
pensar a respeito dessa disciplina. Ela seria antes uma ciência
multidisciplinar que leva em consideração os procedimentos
agrícolas, econômicos, sociais, científicos, técnicos e culturais
da nutrição.

O movimento Slow surgiu na Itália, onde produtores e apreciadores de bons vinhos haviam iniciado campanhas para valorizar o Barolo, uma bebida local que merecia destaque para não cair na vala comum de bebidas que acabam sendo padronizadas, homogeneizadas. E do vinho, gastrônomos do 
Piemonte começaram a se interessar pela promoção da cozinha regional. O grande nome do movimento é Carlo Petrini, que, nos anos 1980, escrevia uma coluna de gastronomia para o jornal il Manifesto. Mas Petrini não é apenas um especialista em gastronomia que escreve em jornais. Ele é também um militante que resolveu mostrar caminhos que podiam se contrapor à pobreza do gosto e sabor do que se come em cadeias de fast food. Com ele, nasceu um movimento que ganhou expressão internacional e adesão de grande número de profissionais que querem promover um alimento bom, limpo e justo. O Slow Food espalhou-se por 130 países e tem uma organização internacional que indica direções, mas é bastante flexível. O movimento tem princípios gerais aceitos por todos os membros. Tem, porém, nuances próprias em cada país ou região. O importante no movimento é a valorização da produção local, a educação do gosto, a convivência em atos de alimentação, o prazer na degustação dos alimentos.

A valorização da velocidade não se resume, como se sabe, à pressa que produziu as redes de fast food mundo afora. Motoristas querem ir mais depressa. Pais querem que seus filhos queimem etapas nos estudos e cheguem à universidade o mais cedo possível. Empresas valorizam executivos que conseguem dar respostas imediatas para desafios de gestão. E por aí vai uma imensa corrente que louva o movimento acelerado como uma das mais importantes virtudes de nosso tempo. Por isso, o Slow Food gerou filhotes em muitos outros setores da vida, do sexo às academias de ginástica, do hall de concertos à sala de aula, da prancheta do designer às viagens de turismo. A obra em análise examina muitos desses desdobramentos. Destaco, a seguir, alguns deles.

\section{Por uma cidade lenta}

O processo de urbanização, desde o fim da Idade Média, elegeu o relógio como a máquina mais importante de nossa civilização. E como observa um grande historiador da cultura (MUMFORD, 1967), o relógio é a única máquina que foi concebida sem qualquer referência a aspectos da natureza. Ele é, nas palavras de Mumford, a primeira máquina abstrata da história. Ele nada imita e, além disso, submete todos os fazeres humanos a tempos e movimentos totalmente artificiais. Cumprir religiosamente o horário, deslocar-se o mais rápido possível de um para outro compromisso, acelerar o tempo e outros comportamentos vinculados a uma vida corrida são marcas profundas dos grandes centros urbanos. E, contraditoriamente, as grandes cidades foram criando obstáculos para usos mais eficientes do tempo. A aceleração da vida acaba provocando imensos congestionamentos.

Um dos primeiros filhotes do Slow Food foi o Cittaslow, um movimento nascido também na Itália, como denuncia o uso do termo citta, para designar 
o movimento. O Cittaslow não sugere soluções para os grandes centros urbanos, para as muitas megalópolis que cresceram assustadoramente nos últimos 50 anos. Ele apenas oferece um roteiro para pequenas cidades, de até 50 mil habitantes, desenvolverem condições para se qualificarem como cidades lentas. Há, portanto, um conjunto de compromissos que os pequenos centros urbanos precisam aceitar para serem reconhecidos com cittaslow.

Em cidades lentas, o compromisso é favorecer uma qualidade de vida na qual deslocamentos sejam feitos a pé ou por meio de transporte de velocidade reduzida. Eventualmente, poderão existir meios de transporte mais rápidos, desde que públicos. Nenhum incentivo é dado ao transporte individual em automóveis. Nas cidades lentas, todos os serviços necessários ao viver cotidiano devem estar a distância que permita que os cidadãos a eles cheguem andando sem atropelo. Como assinalam os autores, "as cidades lentas transformam-se em lugares de troca e de encontros mais que de vias de trânsito para carros" (MENÉTREY; SZERMAN, 2016, p. 67). Outros aspectos são considerados nas cidades lentas. Nelas, espera-se que haja muito verde tanto no entorno como no tecido urbano. Nelas, espera-se também uma articulação com agricultores locais para promover comércio direto de alimentos produzidos na região.

Há, sobretudo na Europa, número significativo de cidades que adotaram o estatuto do Cittaslow. Mas essas cidades são exceções em um mundo no qual núcleos urbanos com mais de um milhão de habitantes são, hoje em dia, coisa banal. Em médio prazo, não há esperança de que as cidades lentas substituam as cidades onde a aceleração da vida continua a predominar. No entanto, a existência de cidades lentas vem funcionando como referência para medidas que podem amenizar o estresse das fast cities. Grandes cidades, em várias partes do planeta, já buscam soluções na direção da desaceleração. Esse, porém, é um caminho difícil, como mostrou recente campanha política vitoriosa na grande metrópole paulista, cujo lema ia em direção inversa ao que propõe o Cittaslow: "Acelera, São Paulo". Mas a análise feita pelos autores sugere que as vantagens da desaceleração das cidades apontam para um horizonte esperançoso.

\section{Uma educação sem atropelos}

Infelizmente, as expectativas sociais de sucesso colocam as crianças em situações de grandes exigências no campo da educação. Os pais querem acelerar a formação de seus herdeiros. Escolas de ponta sobrecarregam seus alunos com número excessivo de disciplinas. $\mathrm{E}$ as famílias acrescentam ao trabalho escolar um grande número de compromissos para as crianças. $\mathrm{O}$ jornalista Carl Honoré, citado pelos autores logo no início do livro, é um crítico do estilo de educação que predomina nas escolas e no lar. Para ele, 
as crianças não têm tempo suficiente para brincar e sonhar. As exigências cada vez maiores no campo da educação não garantem bons resultados. Os autores mostram isso utilizando o exemplo francês:

As pesquisas do PISA (2009) também demonstram que mais, em matéria escolar, não significa necessariamente melhor. A França é o país que mais conta horas de curso no programa escolar da Europa, com 7.500 horas para os alunos de 7 a 15 anos. A Finlândia dispensa apenas 5.500 horas durante os mesmos oito anos (MENÉTREY; SZERMAN, 2016, p. 96).

A observação dos autores foi feita depois de terem comentado que a Finlândia é o país que consegue os melhores resultados nas provas internacionais de aferição dos resultados escolares. Mais tempo, mais exigência nos estudos, maior aceleração da aprendizagem não trazem o esperado sucesso. Podem, ao contrário, resultar em uma educação de menos qualidade e em desinteresse dos alunos pelos estudos.

A análise dos autores não acentua muito as questões de uma educação acelerada. Eles se prendem muito ao cenário francês e sublinham aspectos de constantes reformas da educação que, no geral, fracassam. Ao se voltarem para aspectos mais específicos de propostas de slow education, Menétrey e Szerman preferem reproduzir os 15 princípios de uma educação lenta propostos pelo educador catalão Joan Domenèch. Os 15 princípios aprofundam os requisitos do tempo em educação, propondo maior personalização, alongamento de prazos e menor pressão sobre as crianças.

Não há ainda uma proposta clara sobre planos para uma educação mais lenta. Há apenas a certeza de que as exigências excessivas das escolas não trazem qualquer vantagem para os alunos. Além disso, as exigências sociais de sucesso continuam a favorecer expectativas de que crianças e jovens precisam passar mais tempo nas escolas e complementar sua formação com várias atividades, como a aprendizagem de idiomas estrangeiros e cursos no campo de ciências da computação. A educação, no geral, continua a ser influenciada por ideias que elegem a rapidez entre os valores mais importantes da vida.

\section{Pela volta do viajante}

Outro filhote do Slow Food é o Slow Tourism. A proposta parte de uma crítica feita ao turismo de massa. Até o século 19, poucas pessoas viajavam para terras distantes de seu lar. As deslocações eram demoradas, pois os meios de transporte eram lentos. Mas, historicamente, os humanos sempre buscaram novas paisagens e assim praticamente ocuparam todo o planeta. A curiosidade para conhecer o outro distante e culturas muito diferentes da sua levaram os filhos da nobreza europeia a embarcarem em demoradas 
viagens para mais se educarem. Mas esse era um privilégio dos herdeiros das classes abastadas. Os meios de transporte rápido mudaram esse quadro no século 19, dando início a uma atividade que favorece deslocamentos de milhões de pessoas por todo o planeta. Surgiu e cresceu, assim, o turismo que hoje conhecemos.

A crítica a um turismo que faz pessoas circularem apressadamente por paisagens que elas não têm tempo para apreciar não é nova. No clássico The image: a guide to pseudo-events in America (BOORSTIN, 1992), o autor mostra passantes apressados por atrações criadas exclusivamente para turistas, que consomem uma mercadoria criada para eles, mas não entram em contatos autênticos com o povo e as culturas locais. E tudo acontece às pressas. Em uma semana, turistas chegam a passar por três ou mais localidades.

Para Menétrey e Szerman, o turismo que conhecemos esvaziou o significado das viagens. As pessoas se deslocam, mas não se encontram autenticamente com a cultura, a paisagem e a história dos locais por onde passam. Os tempos apressados dos roteiros de viagem resultam em experiências artificiais. Turistas olham, mas não veem obras de arte, paisagens, obras arquitetônicas, sítios históricos. Fotografam tudo compulsoriamente, mas não registram experiências pessoais que mostrem que entraram em contato com um mundo diferente do seu. O turismo de massa não expande o conhecimento das pessoas.

O Slow Tourism propõe a recuperação do sentido das viagens. Quer eliminar do horizonte os deslocamentos frenéticos de grupos conduzidos por atrações recomendadas por guias que classificam o que deve ser visto sem dar às pessoas oportunidade para experienciar o diferente, para conhecer o que pode enriquecer suas vidas. Além disso, o movimento propõe que a recuperação do sentido original das viagens resulte em atitudes respeitosas do meio ambiente, uma vez que as práticas do fast tourism atual são extremamente predatórias:

Partidário do less is more a nível turístico, o Slow Turismo convida a reduzir o número de experiências durante as viagens e a se concentrar na qualidade, uma vez que o turismo lento significa viver a experiência do tempo na viagem. Viajar de acordo com o seu tempo, levando tempo para apreciar alguns momentos de felicidade em vez de acumular as experiências atropeladas (MENÉTREY; SZERMAN, 2016, p. 147).

\section{Viver sem pressa para viver melhor}

O Slow Movement é um apelo por melhor qualidade de vida. Ele não elimina necessariamente benefícios da velocidade, mas chama atenção para necessidades de moderação em tudo que realizamos. Por essa razão, apelos 
para desacelerar ritmos vêm crescendo na medicina, na educação, no sexo, na jardinagem, na moda, nos livros, na ciência etc. Os autores aprofundam a análise de alguns desses aspectos e listam um número expressivo de opções por ritmos mais sossegados do viver. Em breve nota, chamam atenção para prováveis usos mercadológicos das ideias surgidas a partir do Slow Food. Esse é um perigo que se corre, pois a cultura fast é avassaladora e costuma engolir os movimentos que a contrariam.

Embora a obra destaque consequências do Slow Movement para a educação em capítulo próprio, há que se observar que as tendências de desaceleração são todas elas importantes no plano educacional. O Slow Food, por exemplo, muda profundamente valores promovidos por uma educação que não esteja atenta para o local. Ele recoloca temas de conversação que andam ausentes de uma sociedade que elegeu a globalização como destino fatal. O Slow Food chama atenção não apenas para o prazer de degustar algo diferente, não padronizado, com nuances que podem resultar em descobertas interessantes. Ele chama a atenção para um ritmo que é mais lento, mas que aumenta o prazer de viver experiências de mais qualidade.

\section{Referências}

BOORSTIN, Daniel. The image: a guide to pseudo-events in America. New York: Vintage Books, 1992.

HONORÉ, Carl. Elogio de la lentitud: un movimiento mundial desafia el culto de la velocidad. Buenos Aires: Del Nuevo Extremo, 2005.

MENÉTREY, Sylvain; SZERMAN, Stéphane. Desacelere: ouse diminuir o ritmo e viva melhor. São Paulo: Ed. Senac São Paulo, 2016.

MUMFORD, Lewis. The myth of the machine: technics and human development. New York: Harcourt, Brace \& World, 1967.

WALTERS, Alice; DUANE, Daniel. Edible schoolyard: a universal idea. San Francisco: Cronicle Books, 2008.

Jarbas Novelino Barato

Professor. Doutor em Educação pela Universidade Estadual de Campinas (Unicamp). Mestre em Tecnologia Educacional pela San Diego State University (SDSU).

E-mail: jarbas.barato@gmail.com 